\title{
O USO E OS IMPACTOS DA RECICLAGEM DE CROMO EM indústrias de CURTUMe em Mato Grosso do SUl, Brasil
}

\author{
Usage AND RECYCLING of CHROMIUM at tanNeRIES IN MATo Grosso \\ DO SUL, BRAZIL
}

TÂNIA Christina MARCHESI DE FREITAS

Farmacêutica-Bioquímica pela Universidade Federal de Mato Grosso do Sul (UFMS). Mestre em Desenvolvimento Sustentável pela Universidade Nacional de Brasília (UnB). Doutoranda em Ciências da Saúde, Convênio Centro-Oeste UNB-UFMS-UFGO. Gerente de Controle Sanitário e Mobilização Comunitária da Empresa de Saneamento do Mato

Grosso do Sul (SANESUL). Professora Licenciada da Universidade Estadual de Mato Grosso do Sul (UEMS)

\section{PETR MELNIKOV}

Médico pelo First Moscow Medical Institute (IMMI), Rússia. Químico pela Moscow State University (MSU). Doutor em Química pela Moscow State University (MSU). Professor-Doutor do Departamento de Clínica Cirúrgica do Centro de Ciências Biológicas e da Saúde (CCBS) da Universidade Federal de Mato Grosso do Sul (UFMS)

Recebido: 13/01/06 Aceito: 22/08/06

\section{RESUMO}

Um estudo da dinâmica de emissão de cromo foi realizado em dois curtumes representativos de Mato Grosso do Sul. Apenas cromo III foi encontrado durante a investigação. Foram realizadas extensivas análises químicas de cromo nos efluentes e corpos receptores durante seis meses e os valores obtidos foram comparados com os da legislação existente. Demonstrou-se que, em alguns casos, a concentração de cromo atinge níveis ecologicamente perigosos, pois foram encontrados valores acima do permitido para águas. $\mathrm{O}$ processo de reciclagem de cromo em curtumes mostrou-se como um processo para a normalização das concentrações de cromo nas diferentes etapas de produção e na emissão desse elemento.

PALAVRAS-CHAVE: Curtume, cromo, reciclagem e impactos ambientais.

\section{ABSTRACT}

A study of the dynamics of chromium emissions was carried out at two major tanneries operating in the State of Mato Grosso do Sul. Chromium III was the only species found during the investigation. Extensive chemical analyses for chromium were performed at the effluents and receptive sites for six months and the results were compared with the values required by the existing official acts, showing that they are were above ecologically dangerous levels. The concentrations of chromium in waters also were found to exceed the permissible values, but with a tendency toward reduction. Recycling was found to be the important operation capable of normalizing chrome concentrations at the various steps of production and in the release of this element into the environment.

KEYWORDS: Tannery, chromium, recycling and environmental impact.

\section{INTRODUÇÃO}

O cromo é um elemento bioativo que, embora presente no organismo em pequenas quantidades, realiza importantes funçôes, particularmente no metabolismo da glicose. No entanto, quando em concentrações elevadas, e sobretudo em estado de oxidação diferente de 3, é potencialmente perigoso à saúde e ao equilíbrio ambiental (Nriagu \& Nieboer, '1988).

Dada a toxicidade de seus compostos hexavalentes (mais tóxicos e mais voláteis) e das formas trivalentes (toxicidade essencial), o uso de cromo nas atividades domésticas e industriais tem sido objeto de interesse especial, em termos de sua circulação e de suas emissões na atmosfera, assim como de seu transporte e transformações.

Seus usos mais comuns, e por conseguinte suas principais fontes no meio ambiente, são a mineração e as indústrias de cromagem e de curtimento de couro para confecção de bens de consumo. Ressalte-se que a legislação brasileira impõe uma série de regras rigorosas aos projetos industriais que utilizam esse elemento (Silva \& Pedroza, 2001).

O cromo é usado em grande escala para a transformação de peles de animais em um produto que resiste à biodegradação: o couro. O composto aplicado nesse processo é o sulfato de cromo III - $\mathrm{Cr}_{2}\left(\mathrm{SO}_{4}\right) \cdot \mathrm{xH}_{2} \mathrm{O}-$, comumente referido como sal de cromo (Mota, 2001). O composto promove o enrijecimento da pele, garantindo a preservação do produto final.

O Estado do Mato Grosso do Sul possui o maior rebanho bovino no país, cerca de 25 milhôes de cabeças, ou seja, $13 \%$ do rebanho nacional. Essa oferta de matéria prima aliada aos incentivos fiscais implementados, favorece a instalação de curtumes. No Estado existem cerca de 11 curtumes instalados (SINDICOURO/MS, 2006), sendo que a maioria produz o couro até o produto pré-fabricado conhecido como "wet-blue", tecnicamente denominada as peles curtidas em sais de cromo, que apresenta um tom azulado e pode ser armazenado por longos períodos em estado úmido, sem que venha se decompor. Até o momento, que se saiba, 
não consta nenhum estudo a respeito dos impactos das emissóes do cromo em cursos d'água em Mato Grosso do Sul, desta forma há a necessidade de avaliar as concentraçôes de cromo neste tipo de industria, suas emissões e os impactos causados por esse poluente.

Em projetos industriais de curtumes que incluem o processo de reciclagem, as concentraçõos de cromo nos resíduos líquidos e nos efluentes após o tratamento podem variar de maneira considerável. Essa possibilidade levou algumas indústrias a introduzir tecnologias mais eficientes, com melhor relação custo-benefício, visando minimizar impactos ambientais indesejáveis do uso do cromo. Vem por isso crescendo a tendência à utilização do sistema da reciclagem desse elemento.

Este artigo apresenta um estudo do uso e dos impactos da reciclagem de cromo em indústrias de curtume de Mato Grosso do Sul, valendo-se de métodos analíticos e instrumentais contemporâneos.

\section{MECANISMOS E FORMAS DE ELIMINACÁO DE CROMO NAS INDUSTRIAS DE CURTUME}

O processo de curtimento gera resíduos sólidos e líquidos em elevadas quantidades. Os resíduos líquidos são de composição extremamente complexa e seu tratamento é por isso difícil. Os que derivam das etapas de lavagem, remolho e caleiro perfazem $31 \%$ do total dos efluentes, e os efluentes do banho de cromo somam outros $11 \%$. O restante provém das demais etapas do processo. As características convencionais dos poluentes das diversas etapas são (Bajza, 2001):

a) demanda bioquímica de oxigênio (DBO5): $1600 \mathrm{mg} / \mathrm{L}$;

b) demanda química de oxigênio (DQO): $4600 \mathrm{mg} / \mathrm{L}$;

c) sulfitos: $64 \mathrm{mg} / \mathrm{L}$;

d) cromo total: $76 \mathrm{mg} / \mathrm{L}$.

A remoção completa de cromo III ou sua redução até os níveis permitidos pela legislação ambiental exigem necessariamente investimentos em equipamentos, controle operacional e manutenção, o que torna dispendioso o tratamento dos resíduos. Mesmo assim, o tratamento dos efluentes vem sendo melhorado com a escolha de métodos mais eficazes de remoção.
Constata-se que uma parcela significativa dos efluentes líquidos pode ser reduzida ao se recorrer a um melhor controle do processo. A carga poluidora dessa atividade pode ser minimizada com a redução dos insumos, com o combate às perdas nos processos e com a reutilização dos efluentes (Trindade et al, 2003).

No procedimento tradicionalmente usado, o sulfato de cromo III faz aumentar a concentração desse elemento no resíduo líquido antes que atinja o tanque de equalização. Em alguns curtumes, porém, o pré-tratamento do banho de cromo por meio do reciclo é realizado separadamente e antes do lançamento no tanque de equalização. Mesmo que a equalização sirva para melhorar a homogeneização dos resíduos, o fluxo nunca é completamente balanceado, ocasionando grande variabilidade composicional.

A reciclagem de cromo da água dos banhos de curtimento é importante porque permite reduzir a concentração do elemento nos efluentes e atingir o nível permitido pelos padrões de emissão (Steinbeis Europa Zentrum, 2001).

\section{METODOLOGIA}

\section{Definição dos locais}

Foram selecionados em Mato Grosso do Sul dois curtumes, aqui designados por $\mathrm{A} \mathrm{e} B$, para serem acompanhados durante seis meses. A escolha se baseou em dois critérios. O primeiro foi o de que o produto da indústria fosse do tipo wet blue; o segundo foi o de que apenas um dos dois curtumes fizesse uso do reciclo do banho de cromo.

Desse modo, as indústrias selecionadas apresentaram as seguintes características:

a) Curtume A: produção de couro wet blue sem realizar o reciclo do banho de cromo; tratamento dos efluentes líquidos por meio de decantação e de lagoas de estabilização e deposição dos resíduos sólidos em aterro industrial próprio.

b) Curtume B: produção de couro wet blue, mas utilizando reciclagem do banho de cromo; tratamento dos efluentes por meio do sistema de lodo ativado e deposição dos resíduos sólidos em aterro industrial próprio.

As análises químicas foram realizadas de modo a determinar o cromo trivalente e o hexavalente nos efluen- tes brutos e tratados dos curtumes e nas águas superficiais (a montante e a jusante) dos rios que recebem os efluentes desses curtumes. As amostras de efluentes brutos foram coletadas nos tanques de equalização; as dos efluentes tratados, nas saídas dos sistemas de tratamento.

A quantidade coletada em cada ponto perfez $2 \mathrm{~L}$ de amostragem. Foram utilizados 2 frascos de polietileno de $1 \mathrm{~L}$ cada, nos quais as amostras foram encaminhadas sob resfriamento, em caixas térmicas, ao laboratório. Em um dos frascos adicionaram-se $2 \mathrm{~mL}$ de ácido nítrico concentrado. As amostras acidificadas foram digeridas com ácido nítrico e analisadas para cromo total por meio de espectrofotometria de absorção atômica. As amostras não-acidificadas foram usadas para determinação de cromo hexavalente empregando método colorimétrico com a 1,5-difenilcarbazida.

Foram realizadas seis campanhas de coleta. No curtume A, as coletas ocorreram em setembro, novembro e dezembro de 2004 e de janeiro a abril de 2005. No curtume B, as coletas foram realizadas em setembro e novembro de 2004 e de janeiro a abril de 2005. Tais períodos permitiram considerar o impacto das influências meteorológicas sobre as concentraçôes estudadas.

\section{Análises químicas}

Utilizou-se equipamento de absorção atômica Variam, modelo 220 FS, com chama de ar/acetileno e comprimento de onda de $357,9 \mathrm{~nm}$. Foram construídas curvas de calibração com concentração de cromo variando de 0,0 a $30,0 \mathrm{mg} / \mathrm{L}$. Esse intervalo foi adotado tendo-se em vista as concentrações geralmente encontradas no efluente bruto.

Para as determinações colorimétricas foi usado equipamento $\mathrm{HACH}$, modelo DR 2000. O cromo VI foi determinado aproveitando-se sua reação quantitativa com 1,5-difenilcarbazida em meio ácido. Esse método é comum na determinação de cromo VI contido nos efluentes de curtumes (Walsh \& O’Halloran, 1996a,b).

\section{Análise estatística dos dados}

Os resultados obtidos para cada tipo de efluente foram submetidos ao 
teste de Kruskal-Wallis (5\%) para comparar os curtumes (Zar, 1984).

\section{RESULTADOS E DISCUSSÃO}

\section{Quantidade de insumos utilizados nos processos industriais}

Na Tabela 1 estão resumidos os valores dos diferentes insumos utilizados no processo de curtimento de couro nas duas indústrias.

Comparando-se a quantidade de insumos utilizados nas duas indústrias, verifica-se haver maior gasto das matérias-primas água e cloreto de sódio. Assim, em termos de consumo, a ausência de um sistema de reciclo de cromo implica um aumento de gastos com matérias-primas.

\section{Concentração de cromo nos efluentes brutos e tratados}

As Tabelas 2 e 3 mostram os resultados das análises químicas realizadas em amostras coletadas nos efluentes brutos e tratados dos dois curtumes.

Como se observa nessas tabelas, não foram encontradas quantidades detectáveis de cromo VI para nenhum dos dois curtumes.

Verifica-se na Tabela 3 que as concentraçôes de cromo encontradas nos efluentes brutos na indústria $\mathrm{A}$ (que não utiliza o processo de reciclo do curtimento) variam de $868,8 \mathrm{mg} / \mathrm{L}$ a $104,31 \mathrm{mg} / \mathrm{L}$ de cromo III com mediana de 351,22. Esses valores são mais elevados do que o intervalo de concentração de cromo III encontrado nos efluentes brutos da indústria $B$ (que utiliza o processo de reciclo do curtimento), que variam de $322,17 \mathrm{mg} / \mathrm{L}$ a $38,182 \mathrm{mg} / \mathrm{L}$ e com mediana de 225,03.

Aplicando-se o teste de KruskalWallis, verificou-se não haver diferença significativa $(p>0,05)$ entre os curtumes quanto aos níveis de cromo III nos efluente brutos.

No entanto, apesar do sistema de reciclo de cromo utilizado na indústria $\mathrm{B}$, alguns valores de concentração de cromo nos efluentes brutos se mostraram superiores às médias convencionais de 76 mg/L (UNEP, 1991) em efluentes finais que misturam banhos de caleiro, curtimento e enxugamento (Figura 1).

Tabela I - Quantidades de insumos utilizados no curtimento de peles em dois curtumes. Mato Grosso do Sul, 2004-2005

\begin{tabular}{cccc}
\hline Insumo & Unidade & Curtume A & Curtume B \\
\hline Água & Litros/pele & 276 & 180 \\
Sulfato de cromo III & $\%$ & 5,5 & 5,9 \\
Ácido sulfúrico & $\%$ & 0,3 & 0,3 \\
Cal hidratada & $\%$ & 3,5 & 3,5 \\
Cloreto de sódio & $\%$ & 6 & 1,8 \\
Sulfato de amônia & $\%$ & 3,5 & 4 \\
Sulfato de sódio & $\%$ & 1,4 & 0 \\
\hline
\end{tabular}

Observa-se que a indústria $\mathrm{B}$ emitiu cromo III em concentraçôes de 7,55 a $0,74 \mathrm{mg} / \mathrm{L}$ e com mediana de 3,06. Embora sejam menores que as concentrações emitidas pela indústria A (de 28,10 a $3,47 \mathrm{mg} / \mathrm{L}$ ) e mediana de 12,96, os valores ainda são, em sua maioria, superiores ao limite máximo de $0,5 \mathrm{mg} / \mathrm{L}$ para cromo total estabelecido pela Resolução 357/2005 do CONAMA (Brasil, 2005).

Aplicando-se o teste de KruskalWallis, verificou-se diferença significativa entre os curtumes nos níveis de cromo III nos efluentes tratados $(p>0,05)$.

\section{Flutuação dos dados de efluentes}

As oscilações dos dados referentes ao efluente bruto/tanque de equalização da indústria $\mathrm{A}$, com coeficiente de variação de $70,32 \%$, revelam a dificuldade de operação e controle do sistema de tratamento. Essas variaçōes estão ligadas, sobretudo, à diluição com águas isentas de cromo provenientes de outros banhos. $\mathrm{O}$ volume dessas águas no tanque de equalização produz uma diluição na solução que contém sais de cromo. O coeficiente de variação nos dados do efluente bruto do curtume B foi menor $(50,55 \%)$; as flutuaçōes, aqui, se devem à manutenção e à quantidade de produção, que sofrem grandes oscilaçôes.

A Tabela 4 mostra as concentrações de cromo em função de diferentes taxas de mistura dos banhos de caleiro/curtimento em um experimento.

Os dados de emissões do curtume A mostram concentraçōes que variaram de 3,47 a $28,10 \mathrm{mg} / \mathrm{L}$ de cromo III - acima, portanto, do permitido pela Resolução 357/2005 do CONAMA.
O cromo lançado no corpo receptor pela indústria $\mathrm{B}$ mantém concentraçôes menores (de 0,74 a 7,55 mg/L), porém ainda superiores às permitidas. Mesmo com essas concentraçôes no efluente tratado, o sistema apresentou maior eficiência.

Desse modo, confirmou-se que as variações dos dados produtivos e as emissões de cromo no meio ambiente não apresentam caráter estável, estando sujeitas a bruscas modificaçōes.

\section{Interpretação dos efeitos ecológicos}

Os resultados das análises para cromo total, cromo III e cromo VI no corpo receptor do efluente tratado do curtume A constam na Tabela 5 .

Em termos de preservação ambiental, os níveis de cromo encontrados nos efluentes dos curtumes não são, em sua maioria, aceitáveis. De acordo com a Resolução 357/2005 do CONAMA, o padrão de emissão estabelecido para o elemento é de $0,5 \mathrm{mg} / \mathrm{L}$. Os níveis de cromo admissíveis para as águas estudadas são de $0,05 \mathrm{mg} / \mathrm{L}$.

No entanto, as Tabelas 2 e 3 mostram valores elevados para os curtumes A e B: $28,10 \mathrm{mg} / \mathrm{L} \mathrm{e}$ $7,55 \mathrm{mg} / \mathrm{L}$, respectivamente, ou seja, os níveis admissíveis superam os permitidos em 56 e 15 vezes. Ao mesmo tempo, os níveis mínimos detectados foram $7,55 \mathrm{mg} / \mathrm{L}$ e $0,74 \mathrm{mg} / \mathrm{L}$, superando em 15 e 1,5 vezes, respectivamente, os níveis admissíveis.

O corpo receptor do efluente do curtume A apresenta vazão média de aproximadamente $800 \mathrm{~L} / \mathrm{s}$ no período chuvoso e $300 \mathrm{~L} / \mathrm{s}$ no período seco, apresenta áreas de erosão, assoreamento e de desmatamento da mata ciliar no ponto de coleta. O corpo receptor do 
Tabela 2 - Concentrações de cromo nos efluentes brutos de dois curtumes. Mato Grosso do Sul, 2004-2005

\begin{tabular}{|c|c|c|c|c|c|c|}
\hline \multirow{2}{*}{$\begin{array}{l}\text { Período de } \\
\text { coleta }\end{array}$} & \multicolumn{3}{|c|}{ Curtume A } & \multicolumn{3}{|c|}{ Curtume B } \\
\hline & $\begin{array}{c}\mathrm{Cr} \text { VI } \\
(\mathrm{mg} / \mathrm{L})\end{array}$ & $\begin{array}{c}\mathrm{Cr} \text { III } \\
(\mathrm{mg} / \mathrm{L})\end{array}$ & $\begin{array}{l}\text { Cr total } \\
(\mathrm{mg} / \mathrm{L})\end{array}$ & $\begin{array}{c}\mathrm{Cr} \text { VI } \\
(\mathrm{mg} / \mathrm{L})\end{array}$ & $\begin{array}{c}\mathrm{Cr} \text { III } \\
(\mathrm{mg} / \mathrm{L})\end{array}$ & $\begin{array}{l}\text { Cr total } \\
(\mathrm{mg} / \mathrm{L})\end{array}$ \\
\hline Setembro & ND & 558,43 & 558,43 & ND & 38,18 & 38,18 \\
\hline Novembro & ND & 226,44 & 226,44 & ND & 201,31 & 201,31 \\
\hline Dezembro & ND & 104,31 & 104,31 & - & - & - \\
\hline Janeiro & ND & 351,22 & 351,22 & ND & 279,84 & 279,84 \\
\hline Fevereiro & ND & 152,81 & 152,81 & ND & 248,75 & 248,75 \\
\hline Março & ND & 868,8 & 868,8 & ND & 322,17 & 322,17 \\
\hline Abril & ND & 774,8 & 774,8 & ND & 138,20 & 138,20 \\
\hline Estatística & \multicolumn{3}{|c|}{ Curtume A } & \multicolumn{3}{|c|}{ Curtume B } \\
\hline Mínimo & \multicolumn{3}{|c|}{104,31} & \multicolumn{3}{|c|}{38,18} \\
\hline Máximo & \multicolumn{3}{|c|}{868,8} & \multicolumn{3}{|c|}{322,17} \\
\hline Mediana & \multicolumn{3}{|c|}{351,22} & \multicolumn{3}{|c|}{225,03} \\
\hline Média aritmética & \multicolumn{3}{|c|}{433,83} & \multicolumn{3}{|c|}{204,74} \\
\hline Soma dos postos (1) & \multicolumn{3}{|c|}{58} & \multicolumn{3}{|c|}{33} \\
\hline$p$ (Kruskal-Wallis) & \multicolumn{3}{|c|}{0,1958} & & & \\
\hline
\end{tabular}

ND: Nada detectado

(1) Valores não significativamente diferentes segundo o teste de Kruskal-Wallis $(p>0,05)$

Tabela 3 - Concentração de cromo nos efluentes tratados de dois curtumes. Mato Grosso do Sul, 2004-2005

\begin{tabular}{|c|c|c|c|c|c|c|}
\hline \multirow{2}{*}{$\begin{array}{l}\text { Período de } \\
\text { coleta }\end{array}$} & \multicolumn{3}{|c|}{ Curtume A } & \multicolumn{3}{|c|}{ Curtume B } \\
\hline & $\begin{array}{c}\mathrm{Cr} \text { VI } \\
(\mathrm{mg} / \mathrm{L})\end{array}$ & $\begin{array}{c}\text { Cr III } \\
(\mathrm{mg} / \mathrm{L})\end{array}$ & $\begin{array}{l}\text { Cr total } \\
(\mathrm{mg} / \mathrm{L})\end{array}$ & $\begin{array}{c}\mathrm{Cr} \text { VI } \\
(\mathrm{mg} / \mathrm{L})\end{array}$ & $\begin{array}{c}\mathrm{Cr} \text { III } \\
(\mathrm{mg} / \mathrm{L})\end{array}$ & $\begin{array}{l}\text { Cr total } \\
(\mathrm{mg} / \mathrm{L})\end{array}$ \\
\hline Setembro & ND & 24,80 & 24,80 & ND & 7,55 & 7,55 \\
\hline Novembro & ND & 23,47 & 23,47 & ND & 3,86 & 3,86 \\
\hline Dezembro & ND & 11,19 & 11,19 & - & - & - \\
\hline Janeiro & ND & 12,96 & 12,96 & ND & 3,97 & 3,97 \\
\hline Fevereiro & ND & 9,17 & 9,17 & ND & 2,25 & 2,25 \\
\hline Março & ND & 3,47 & 3,47 & ND & 1,30 & 1,30 \\
\hline Abril & ND & 28,10 & 28,10 & ND & 0,74 & 0,74 \\
\hline Estatística & \multicolumn{3}{|c|}{ Curtume A } & \multicolumn{3}{|c|}{ Curtume B } \\
\hline Mínimo & \multicolumn{3}{|c|}{3,47} & \multicolumn{3}{|c|}{0,74} \\
\hline Máximo & \multicolumn{3}{|c|}{28,1} & \multicolumn{3}{|c|}{7,56} \\
\hline Mediana & \multicolumn{3}{|c|}{12,96} & \multicolumn{3}{|c|}{3,06} \\
\hline Média aritmética & \multicolumn{3}{|c|}{16,17} & \multicolumn{3}{|c|}{3,27} \\
\hline Soma dos postos (1) & \multicolumn{3}{|c|}{67} & \multicolumn{3}{|c|}{24} \\
\hline$p$ (Kruskal-Wallis) & \multicolumn{3}{|c|}{0,0101} & & & \\
\hline
\end{tabular}

ND: Nada detectado

(1) Valores significativamente diferentes segundo o teste de Kruskal-Wallis $(p<0,05)$ 


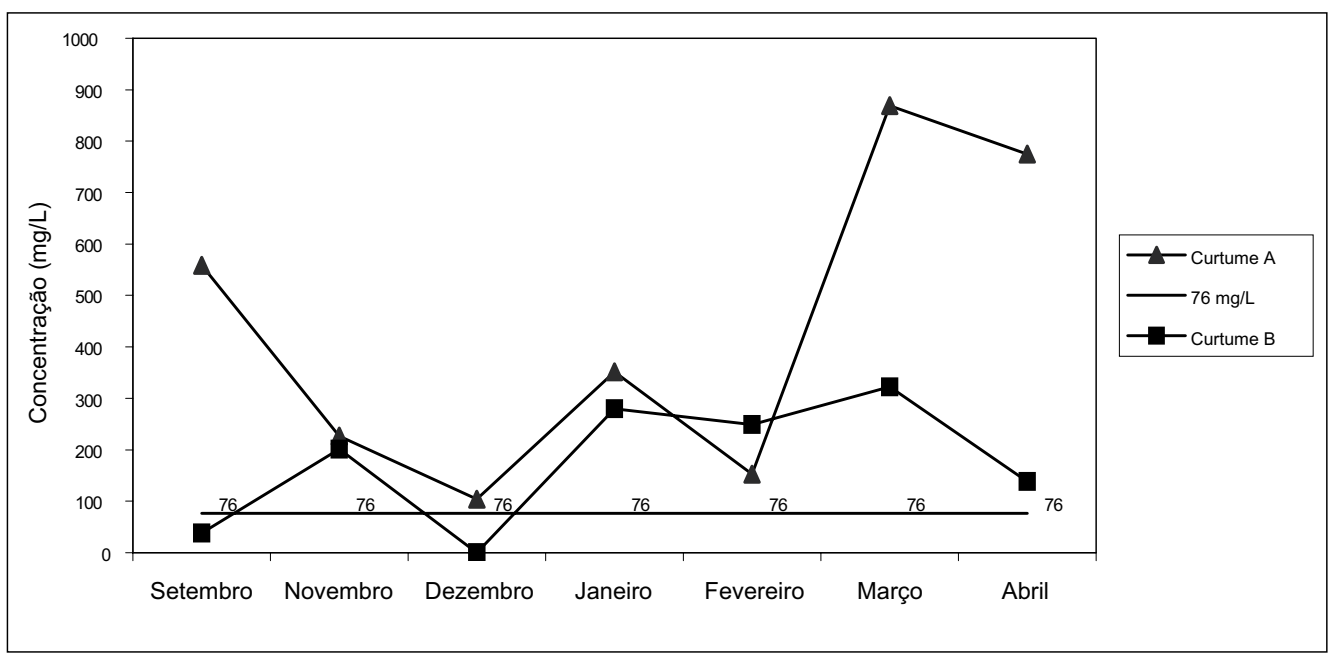

Figura I - Dinâmica de cromo III nos efluentes brutos de dois curtumes. Mato Grosso do Sul, 2004-2005

Tabela 4 - Concentrações de cromo em função das taxas de misturas. Dados experimentais

\begin{tabular}{cc}
\hline Taxa de mistura de caleiro/curtimento & Concentração de cromo (mg/L) \\
\hline $1: 9$ & 308 \\
$3: 7$ & 188 \\
$5: 5$ & 66 \\
$7: 3$ & $<1$ \\
$9: 1$ & $<1$ \\
\hline
\end{tabular}

Fonte: Bajza, 2000

Tabela 5 - Concentração de cromo no corpo receptor do efluente do curtume A. Mato Grosso do Sul, 2004-2005

\begin{tabular}{ccccccc}
\hline $\begin{array}{c}\text { Período de } \\
\text { coleta }\end{array}$ & $\begin{array}{c}\mathrm{Cr} \mathrm{VI} \\
(\mathrm{mg} / \mathrm{L})\end{array}$ & $\begin{array}{c}\text { Montante } \\
\text { Cr III } \\
(\mathrm{mg} / \mathrm{L})\end{array}$ & $\begin{array}{c}\text { Cr total } \\
(\mathrm{mg} / \mathrm{L})\end{array}$ & $\begin{array}{c}\mathrm{Cr} \mathrm{VI} \\
(\mathrm{mg} / \mathrm{L})\end{array}$ & $\begin{array}{c}\text { Jusante } \\
\mathrm{Cr} \text { III } \\
(\mathrm{mg} / \mathrm{L})\end{array}$ & $\begin{array}{c}\text { Cr total } \\
(\mathrm{mg} / \mathrm{L})\end{array}$ \\
\hline Setembro & $\mathrm{ND}$ & $\mathrm{ND}$ & $\mathrm{ND}$ & $\mathrm{ND}$ & 0,49 & 0,49 \\
Novembro & $\mathrm{ND}$ & $\mathrm{ND}$ & $\mathrm{ND}$ & $\mathrm{ND}$ & 0,12 & 0,12 \\
$\begin{array}{c}\text { Dezembro } \\
\text { Janeiro }\end{array}$ & $\mathrm{ND}$ & 0,04 & 0,04 & $\mathrm{ND}$ & 0,06 & 0,06 \\
Fevereiro & $\mathrm{ND}$ & 0,08 & 0,08 & $\mathrm{ND}$ & 0,11 & 0,11 \\
Março & $\mathrm{ND}$ & 0,01 & 0,01 & $\mathrm{ND}$ & 0,06 & 0,06 \\
Abril & $\mathrm{ND}$ & $\mathrm{ND}$ & $\mathrm{ND}$ & $\mathrm{ND}$ & 0,07 & 0,07 \\
\hline
\end{tabular}

ND: Nada detectado 
efluente do curtume B apresenta vazão de aproximadamente $240 \mathrm{~L} / \mathrm{s}$ no período seco e mata ciliar nativa na área do ponto de coleta.

No caso do curtume B, as análises realizadas no corpo receptor mostraram ausência de cromo, sob qualquer forma. Já os valores de cromo encontrados no corpo receptor do efluente do curtume A alcançaram níveis máximos de $0,49 \mathrm{mg} / \mathrm{L}$, sobrepassando dez vezes o admissível para águas. O nível mínimo de cromo encontrado, de $0,06 \mathrm{mg} / \mathrm{L}$, supera o admissível em apenas 1,2 vez. Observa-se a ocorrência de um efeito cumulativo, pois nas águas a montante do lançamento do efluente do curtume A já ocorre presença de cromo.

Do ponto de vista ecológico, os níveis de emissão são mais preocupantes, pois em todas as análises os valores obtidos não foram aceitáveis. A contaminação decorrente da emissão pode causar efeitos nocivos à vida aquática, afetando desde algas até organismos superiores, como por exemplo peixes (Nriagu \& Nieboer, 1988). Os efeitos da bioacumulação, a longo prazo, nem sempre são previsíveis.

\section{Avaliação dos dados com relação à legislação vigente}

Apesar de o Brasil apresentar uma legislação ambiental que estabelece parâmetros para a proteção ao meio ambiente e que visa diminuir os riscos à saúde humana, na maioria dos casos em concordância com padrões internacionais, essa legislação infelizmente não vem sendo devidamente aplicada. Os resultados de emissão de cromo encontrados no presente estudo foram superiores aos permitidos $(0,5 \mathrm{mg} / \mathrm{L}$ de cromo total) e demonstram que os órgãos encarregados da fiscalização e controle atuam ineficientemente. Isso, naturalmente, aponta a necessidade de se contar com melhor capacitação de pessoal e com maior incentivo.

Países desenvolvidos vêm apresentando a tendência de não aceitar tecnologias "incômodas" em seus territórios, mas estas estão, muitas vezes, sendo deslocadas para países em desenvolvimento. A Europa, por exemplo, tem introduzido regulamentaçôes e recomendaçôes que estão promovendo a transferência da etapa de produção de couro com o uso de cromo, mais problemática, para países em desenvol- vimento, enquanto a parte lucrativa das operaçôes permanece sendo realizada nos países da Comunidade Européia.

Tal fato em si não constitui, porém, problema grave, desde que os países em desenvolvimento implementem medidas para capacitar técnicos, organizar quadros e elaborar mecanismos eficientes de controle que possam beneficiar os demais países envolvidos no processo produtivo.

\section{CONCLUSÕES}

Foram estudadas as formas químicas de cromo emitidas em dois curtumes, sendo encontrada apenas a forma trivalente.

Foi demonstrado que a presença do reciclo de cromo é um fator de diminuição do consumo de matériasprimas.

Os resultados obtidos com os efluentes brutos não revelaram significativa diferença nos níveis de cromo III dos dois curtumes.

Os resultados obtidos com os efluentes tratados foram comparados com os níveis estipulados pela legislação, revelando que as emissões podem alcançar níveis ecologicamente perigosos.

Os níveis de cromo nas águas dos corpos receptores dos dois curtumes também foram maiores que os permitidos pela legislação vigente, embora mostrando tendência à redução.

\section{AGRADECIMENTOS}

Os autores agradecem a cooperação dos curtumes envolvidos, da Empresa de Saneamento de Mato Grosso do Sul (SANESUL) e do Laboratório LAQUA da Universidade Federal de Mato Grosso do Sul, com agradecimento especial ao mestre José Luís Gonçalves.

\section{REFERÊNCIAS}

BAJZA, Z; VRCEK, I.V. Water quality analysis of mixtures obtained from tannery waste effluents. Ecotoxicology and Environmental Safety, v. 50, n. 1, p. 15-18, 2001. Disponível em: <http://www. idealibrary.com.on>. Acesso em: 12 fev. 2005.

BRASIL. Resolução CONAMA n. ${ }^{\circ}$ 357, 25 de março de 2005.

MOTA, J.S. Eco-eficiência: avaliação de sustentabilidade de industria do couro no MS. 2001. Dissertação (Mestrado em Desenvolvimento Sustentável) - UnB, Brasília. 2001.
NRIAGU, J. O.; NIEBOER, E. Chromium in the natural and human environments. Ontario: Wiley Inter-Science, 1988.

SILVA, C. S.; PEDROZA, M.F.M. Ecotoxicologia do cromo e seus compostos. Salvador: CRA, 2001.

STEINBEIS EUROPA ZENTRUM, 2001. System for Chromium from Industrial Wastewater. Disponível em: <http://www.steinbeis-europa. de/en/index.php4>. Acesso em: 12 fev. 2005.

TRINDADE, M.C.; MACHADO,R.; ROMANELLI, M. Monitoramento do impacto ambiental da atividade de beneficiamento do couro no meio hidrico. In: 22० CONGRESSO BRASILEIRO DE ENGENHARIA SANITÁRIA E AMBIENTAL, Anais..., Joinville: [s.n.], 2003.

UNEP. United Nations Environment Programme. A workbook for trainers: Cleaner production in Leather Tanning. UNEP, 1991.

WALSH, A.R.; O'HALLORAN, J. Chromium speciation in tannery effluent - I. An assessment of techniques and the role of organic $\mathrm{Cr}$ (III) complexes. Wat. Res., v. 30, n. 10, p. 2393-2400, 1996a.

WALSH, A. R.; O'HALLORAN, J. Chromium speciation in tannery effluent - II. Speciation in effluent and in a receiving estuary. Wat. Res., v. 30, n. 10, p. 2401-2412, 1996 b.

ZAR, J.H. Biostatistical analysis. 2th ed. New Jersey: Prentice Hall, 1984.

Endereço para correspondência:

Tânia Christina Marchesi de Freitas

SANESUL - Empresa de

Saneamento de Mato Grosso do

Sul

GELMC- Gerência de Controle

Sanitário e Mobilização

Comunitária-Laboratório Central

Rua Estrela do Sul , 301

Bairro Vilas Boas

7905 I-250 Campo Grande - MS

- Brasil

Tel. (67)334 I-4998

E-mail: taniamarchesi@sanesul.ms.gov.br 